\title{
Alternaria Spots in Tomato Leaves Differently Delayed by Four Plant Essential Oil Vapours
}

\author{
*Corresponding author \\ Tel: +82-55-751-3251 \\ Fax: +82-55-751-3257 \\ E-mail: jkhong@gntech.ac.kr \\ ORCID \\ https://orcid.org/0000-0002-9161-511X
}

Received October 31, 2018

Revised November 14, 2018

Accepted November 14, 2018

\author{
Jeum Kyu Hong $\mathbb{D}^{1 *}{ }^{*}$, Yeon Sook Jo ${ }^{1}$, Dong Hyun Ryoo ${ }^{1}$, Ji Hwan Jung ${ }^{1}$, \\ Hyun Ji Kwon', Young Hee Lee', Seog Won Chang ${ }^{2}$, and Chang-Jin Park ${ }^{3}$ \\ ${ }^{1}$ Department of Horticultural Science, Gyeongnam National University of Science and Technology \\ (GNTech), Jinju 52725, Korea \\ ${ }^{2}$ Department of Golf Course Management, Korea Golf University, Hoengseong 25247, Korea \\ ${ }^{3}$ Deparment of Bioresources Engineering, Sejong Univerity, Seoul 05006, Korea
}

\begin{abstract}
Alternaria leaf spot disease has been a concern during a tomato production in greenhouse. In vitro antifungal activities of vapours of four plant essential oils, cinnamon oil, fennel oil, origanum oil and thyme oil, were investigated during in vitro conidial germination and mycelial growth of Alternaria alternata causing the tomato leaf spots to find eco-friendly alternatives for chemical fungicides. The four plant essential oils showed different antifungal activities against in vitro conidial germination of $A$. alternata in dose-dependent manners, and cinnamon oil vapour was most effective to suppress the conidial germination. The four plant essential oils showed similar antifungal activities against the in vitro mycelial growth of A. alternata in dosedependent manners, but low doses of thyme oil vapour slightly increased in vitro mycelial growth of $A$. alternata. Necrotic lesions on the A. alternata-inoculated tomato leaves were reduced differently depending on kinds and concentrations of plant essential oils. Delayed conidial germination and germ-tube elongation of $A$. alternata were found on the tomato leaves treated with cinnamon oil and origanum oil vapours at $6 \mathrm{hpi}$. These results suggest that volatiles from cinnamon oil and origanum oil can be provided as alternatives to manage Alternaria leaf spot during the tomato production eco-friendly.
\end{abstract}

Keywords: Alternaria alternata, Disease management, Eco-Friendly, Plant essential oil vapour, Tomato

\section{Introduction}

Tomato plants have been infected by several Alternaria species including A. alternata, A. solani and A. tenuissima causing early blight and leaf spot symptoms (Agamy et al., 2013; Chaerani and Voorrips, 2006; Egusa et al., 2009; Jambhulkar et al., 2016; Prasad and Upadhyay, 2010). A. alternata invaded many organs of the tomato plants, and caused leaf blight, stem canker and fruit rot of tomato plants (Gherbawy

Research in Plant Disease

pISSN 1598-2262, elSSN 2233-9191

www.online-rpd.org et al., 2018; Grogan et al., 1975; Spalding, 1980). A. alternataproduced toxic metabolites such as AAL toxin, alternariol, alternariol monomethyl ether and tenuazonic acid might be involved in the fungal pathogenicity to tomato plants (Egusa et al., 2009; Meena et al., 2016). A variety of chemical and biological controls of tomato early blight caused by Alternaria solani infection have been suggested (Abu-El Samen et al., 2016; Brame and Flood, 1983; Song et al., 2011; Spletzer and Enyedi, 1999). Several chemical fungicides were suggested to control diseases by A. alternata in tomato plants and fruits (Abdel-Mallek et al., 1995; Malathrakis, 1983; Spalding, 1980). However, recent occurrence of fungicide-resistant isolates of A. alternata and $A$. solani in tomato fields has warned of fre- 
quent uses of the chemical fungicides (Chavan et al., 2017). Only limited information has been available for eco-friendly management of A. alternata-mediated tomato diseases using antagonistic bacteria and plant defence-inducing chemical agents. Different bacterial strains of Pseudomonas spp. such as $P$. fluorescens, P. putida and P. aeruginosa inhibited in vitro mycelial growth of $A$. alternata causing a damping-off of tomato seedlings (Hammami et al., 2013). Application of whey compost-tea and rhizobacteria such as Serratia liquefaciens and Pseudomonas putida in soils decreased disease severity of tomato leaves inoculated with A. alternata (Pane et al., 2012; Schuhegger et al., 2006). Pretreatment with salicylic acid mediated induced disease resistance in tomato leaves against challenging A. alternata inoculation, and both L-glutamate and $x$-aminobutyric acid induced resistance and reduced tomato fruit rot caused by $A$. alternata (Esmailzadeh et al., 2008; Yang et al., 2017a, 2017b).

Application of plant essential oils has been effective to reduce bacterial and fungal diseases in various horticultural crops and suggested as one of the eco-friendly alternatives for disease management by chemical pesticides. In our previous studies, soil-drenching clove oil solution significantly reduced tomato bacterial wilt by Ralstonia pseudosolanacearum (Lee et al., 2012). Distinctly suppressed in vitro conidial germination and mycelial growth of Colletotrichum gloeosporioides were demonstrated by treatment with cinnamon oil and clove oil vapours, and followed by reduced anthracnose lesions on pepper fruits treated with the two vapours (Hong et al., 2015). Recently, different in vitro antifungal activities of four plant essential oils, cinnamon oil, fennel oil, origanum oil and thyme oil, were investigated on Fusarium oxysporum f. sp. fragariae that causes Fusarium wilt in strawberry plants, although in planta crop protection efficacies were not evaluated yet, because in vitro and/or in planta antifungal activities of these four plant essential oils were prevalently demonstrated against diverse plant pathogenic fungal species (Park et al., 2017).

Diverse plant essential oils inhibiting Alternaria spp. including A. alternata have been shown to control diseases in many crops such as citrus, potato and tomato and summarised in Table 1. Essential oils from Cretan oregano, thyme, fennel, bay laurel and French lavender showed different in vitro antifungal activities during conidial germination, germ tube elongation and mycelial growth of $A$. alternata causing black rot in Minneola tangelo fruits (Soylu and Kose, 2015). However, control efficacies of the citrus black rot disease by the plant essential oils were not evaluated. Essential oils from carnation, caraway and thyme plants have shown in vitro antifungal activities against $A$. solani as well as reducing effects of early blight of potato plants in fields leading to increased potato tube yields (El-Mougy, 2009). Early blight in tomato seedlings and black rot in tomato fruits by A. alternata infection could be controlled by origanum oil and citronella oil treatments, respectively (Chen et al., 2014; Pérez-González et al., 2016). Thyme oil exerted both antifungal activity and disease control effect on in vitro growth of $A$. alternata and $A$. alternata-infected tomato fruits via fumigation and contact treatments (Feng et al., 2011).

In this study, we applied the four plant essential oils to A. alternata to investigate their antifungal activities to suppress in vitro conidial germination and mycelial growth of $A$. alternata, as well as to control Alternaria leaf spot disease in tomato leaves. Fungal developments regulated by the plant essential oils on the inoculated leaves were also observed microscopically.

Table 1. In vitro antifungal activities against Alternaria alternata and disease reduction efficacies of plant essential oils

\begin{tabular}{lccl}
\hline Plant essential oils & in vitro activity & Disease reduction & \multicolumn{1}{c}{ Reference } \\
\hline Cinnamon oil & M & - & Sukatta et al., 2008 \\
Citronella oil & C, M & Tomato fruits & Chen et al., 2014 \\
Clove oil & M & - & Sukatta et al., 2008 \\
Fennel oil & M & - & Soylu and Kose, 2015 \\
Origanum oil & C, GT, M & - & Soylu and Kose, 2015 \\
Peppermint oil & M & Tomato fruits & Abd-Alla et all, 2009 \\
Thyme oil & C, M & Ponkan tangerine fruits & Perina et al., 2015 \\
\hline
\end{tabular}

C, conidial germination; GT, germ tube elongation; $M$, mycelial growth. 


\section{Materials and Methods}

Fungal culture. Alternaria alternata KACC 40019 was originated from diseased sesame plant showing leaf blight symptom, and maintained on 1/2-strength potato dextrose agar (PDA) at $25^{\circ} \mathrm{C}$ under dark condition. The conidial suspension was obtained from 6 day old-cultured colonies on the PDA using pouring quarterly diluted (1/4) potato dextrose broth. Concentration of the conidial suspension was adjusted using a haemacytometer under a light microscope. To obtain mycelial agar plugs ( $5 \mathrm{~mm}$ in diameter) from the growing colony edge, $A$. alternata was inoculated on the center of PDA media and cultured for 6 days at $25^{\circ} \mathrm{C}$ under dark condition.

Plant growth. Tomato plants (cv. Cupirang) were grown in a commercial soil mixture 'Toshil' in pots ( $8 \mathrm{~cm}$ in diameter, $7.5 \mathrm{~cm}$ in height) in a walk-in growth at $26-28^{\circ} \mathrm{C}$ in the daytime and at $22-24^{\circ} \mathrm{C}$ in the night under a 12-h fluorescent light illumination as slightly modified method described in our previous studies (Hong et al., 2016). Second true leaves from the bottom were detached from the 5-leaf stages of tomato plants and used for the fungal inoculation.

\section{Preparation of paper discs harbouring plant essen-} tial oils. Four plant essential oils cinnamon oil, fennel oil, origanum oil and thyme oil were purchased and prepared in paper discs as described in our previous studies (Hong et al., 2015; Park et al., 2017). Each plant essential oil was dropped onto sterile paper discs (8 $\mathrm{mm}$ in diameter) to contain $0,0.1$, $0.2,0.5,1,2$ and $5 \mu \mathrm{l} /$ paper disc, and the paper discs were attached inside the covers of circular Petri dishes, square dishes and plastic boxes for in vitro conidial germination, in vitro mycelial growth inhibition and in planta protection assay, respectively, to exert their volatile activities. Final vapour concentrations of each plant essential oil for in vitro conidial germination and mycelial growth inhibition assays as well as for in planta protection assay were calculated and summarised in Table 2.

\section{Inhibition of in vitro conidial germination and mycelial} growth of A. alternata. Antifungal activities of vapours of the four plant essential oils against in vitro conidial germination and mycelial growth of A. alternata were evaluated as experimental procedures described in our previous studies
Table 2. Concentration of plant essential oil volatiles s used in this study for in vitro antifungal activities and in planta crop protection

\begin{tabular}{cccc}
\hline $\begin{array}{c}\text { Plant } \\
\text { essential oils } \\
(\boldsymbol{\mu l} / \text { paper disc) }\end{array}$ & $\begin{array}{c}\text { germination } \\
\left(\boldsymbol{\mu l} / \mathbf{c m}^{3} \text { air) }\right.\end{array}$ & $\begin{array}{c}\text { in vitro } \\
\text { mycelial } \\
\text { growth } \\
\left(\mu \mathrm{l} / \mathbf{c m}^{3} \text { air }\right)\end{array}$ & $\begin{array}{c}\text { in planta } \\
\text { protection } \\
\left(\boldsymbol{\mu l} / \mathbf{c m}^{3} \text { air }\right)\end{array}$ \\
\hline 0.1 & 0.00077 & 0.0025 & 0.00019 \\
0.2 & 0.00154 & 0.0050 & 0.00038 \\
0.5 & 0.00385 & 0.0125 & 0.00095 \\
1 & 0.00772 & 0.0250 & 0.00190 \\
2 & 0.01538 & 0.0500 & 0.00380 \\
5 & 0.03846 & 0.1000 & 0.00950 \\
\hline
\end{tabular}

(Hong et al., 2015; Park et al., 2017). Conidial suspensions treated with different concentrations of the plant essential oil vapours on glass slides were incubated in plastic square dishes for $3 \mathrm{~h}$ at $25^{\circ} \mathrm{C}$ under dark and humid conditions, and numbers of germinated conidia and total conidia were measured under a light microscope. Conidial germination (\%) of the vapour-treated samples was compared to the conidial germination on the mock-treated control. For mycelial growth inhibition assay, fungal colony diameters formed on the PDA media were measured at 6 days after culture at $25^{\circ} \mathrm{C}$ under dark condition. Relative mycelial growth was calculated compared to the colony diameter on the mock-treated control. Independent experiments were conducted repeatedly four times for means and standard errors, and four replicates were prepared for each experiment.

Fungal inoculation and disease evaluation. One drop $(10 \mu \mathrm{l})$ of the conidial suspension $\left(2 \times 10^{5}\right.$ conidia/ml) of the A. alternata was inoculated onto centre of adaxial surface of the detached tomato leaves, and the inoculated leaves were placed on sterile water-saturated gauzes laid in plastic boxes at the bottom at $25^{\circ} \mathrm{C}$ to allow the necrotic spot disease symptom development under humid and dark conditions. Lesion diameters were measured at 5 days post-inoculation (dpi). Independent experiments were conducted repeatedly four times for means and standard errors, and four replicates were prepared for each experiment.

Fungal development including conidial germination and germ-tube elongation on the inoculated tomato leaves were observed at 6 hours post-inoculation (hpi) under a light microscopy after fungal staining with lactophenol-trypan blue solution after clearing chlorophylls of the leaf tissues with 
boiling ethanol (Park et al., 2017). Independent experiments were conducted repeatedly three times for means and standard errors of conidial germination and germ-tube length of A. alternata on the inoculated leaves, and eight photos were prepared for each experiment.

Statistical analyses. Data were subjected to analysis of variance (ANOVA) using SAS version 9.1 (SAS Institute, Inc., Cary, NC, USA) to determine effects of plant essential oil treatments on in vitro growth of $A$. alternata, disease suppression and the fungal development on the leaves. Means were compared by least significant difference (LSD) test at $P<0.05$. Graphs were prepared using SigmaPlot 10.0 (Systat Software, Inc., San Jose, CA, USA).

\section{Results}

\section{Antifungal activities of the four plant essential oils} against in vitro conidial germination of $A$. alternata. In vitro conidial germination of $A$. alternata was differently inhibited by treatments with vapours of the four different plant essential oils (Fig. 1). The lowest dose of cinnamon oil ( $0.1 \mu \mathrm{l} /$ disc) resulted in drastic suppression of the conidial germination by ca. $35.1 \%$, and doubling dose to $0.2 \mu \mathrm{l} /$ disc more decreased the conidial germination by ca. $19.4 \%$. Increasing doses to $0.5-5 \mu \mathrm{l} /$ disc only led slightly augmented antifungal activities against the conidial germination. Antifungal activity of fennel oil against the conidial germination was demonstrated but relatively higher doses were necessary for reducing the germination below the $50 \%$ level. The conidial germination was first inhibited by $0.5 \mu \mathrm{l} /$ disc of fennel oil to ca. $87 \%$ and then increasing doses of the fennel oil to $0.5,1$, 2 and $5 \mu \mathrm{l} /$ disc gradually decreased the conidial germination to ca. $80.4,72.8,38.2$ and $25.9 \%$, respectively. Treatment with origanum oil vapour showed dose-dependent antifungal activity against the conidial germination. Increasing dose of origanum oil to $0.1,0.2,0.5$ and $1 \mu \mathrm{l} /$ disc resulted in decreases in the conidial germination by ca. $71.6,42.1,21.6$ and $16.3 \%$, respectively. However, more than $1 \mu \mathrm{l} /$ disc of origanum oil could not significantly increase the suppression efficacies against the conidial germination. Thyme oil also showed dose-dependent antifungal activity against the conidial ger-

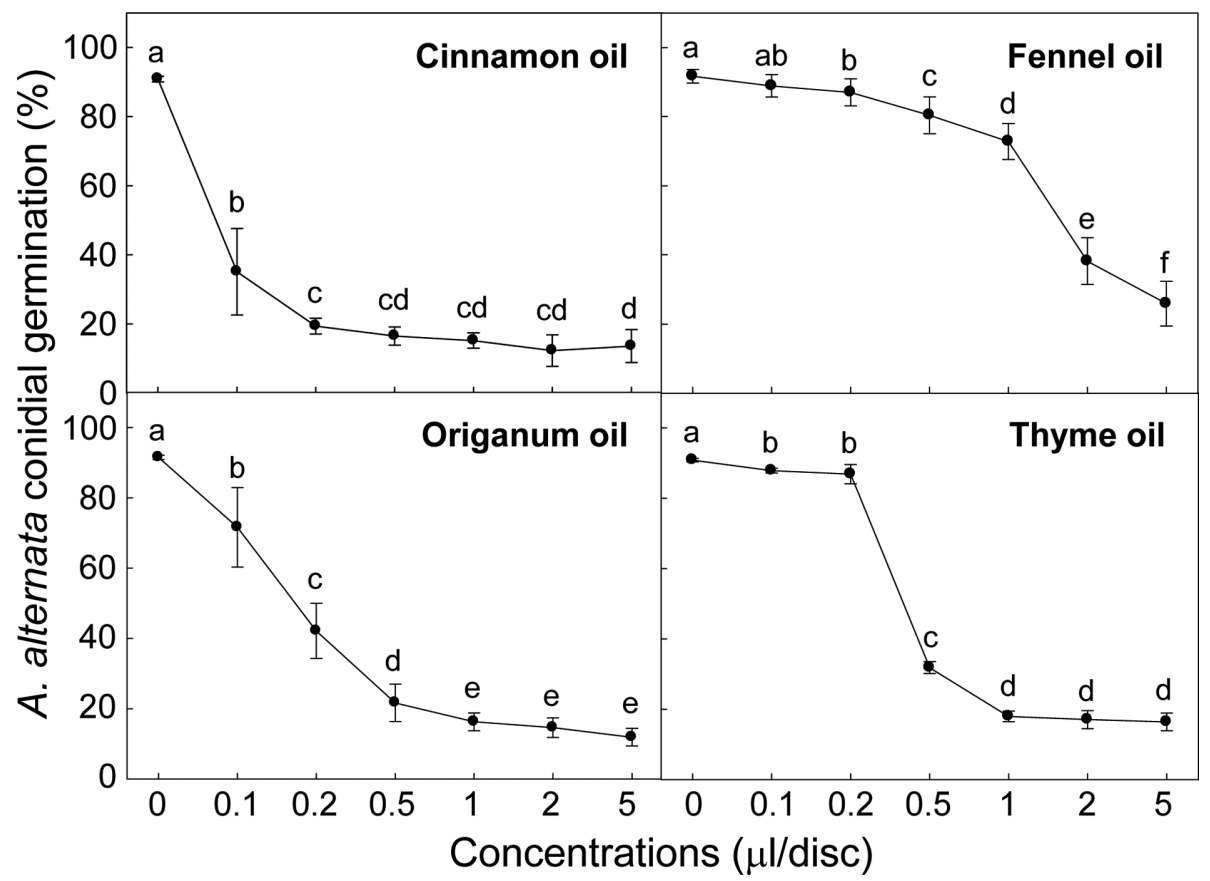

Fig. 1. Conidial germination of Alternaria alternata inhibited by volatiles of four different plant essential oils, cinnamon oil, fennel oil, origanum oil and thyme oil. Germinated conidia of $A$. alternata on the glass slides by treatment with different doses $(0,0.1,0.2,0.5,1,2$ and $5 \mathrm{\mu l} / \mathrm{disc}$ ) of each volatile essential oil were observed under a light microscope. Relative conidial germination (\%) affected by different doses of each essential oil was shown as percentage of the conidial germination. Error bars represent the standard errors of the mean conidial germination of four independent experimental replications. Means followed by the same letter are not significantly different at $5 \%$ level by least significant difference test. The same letter above bars represented no significant difference between treatments. 

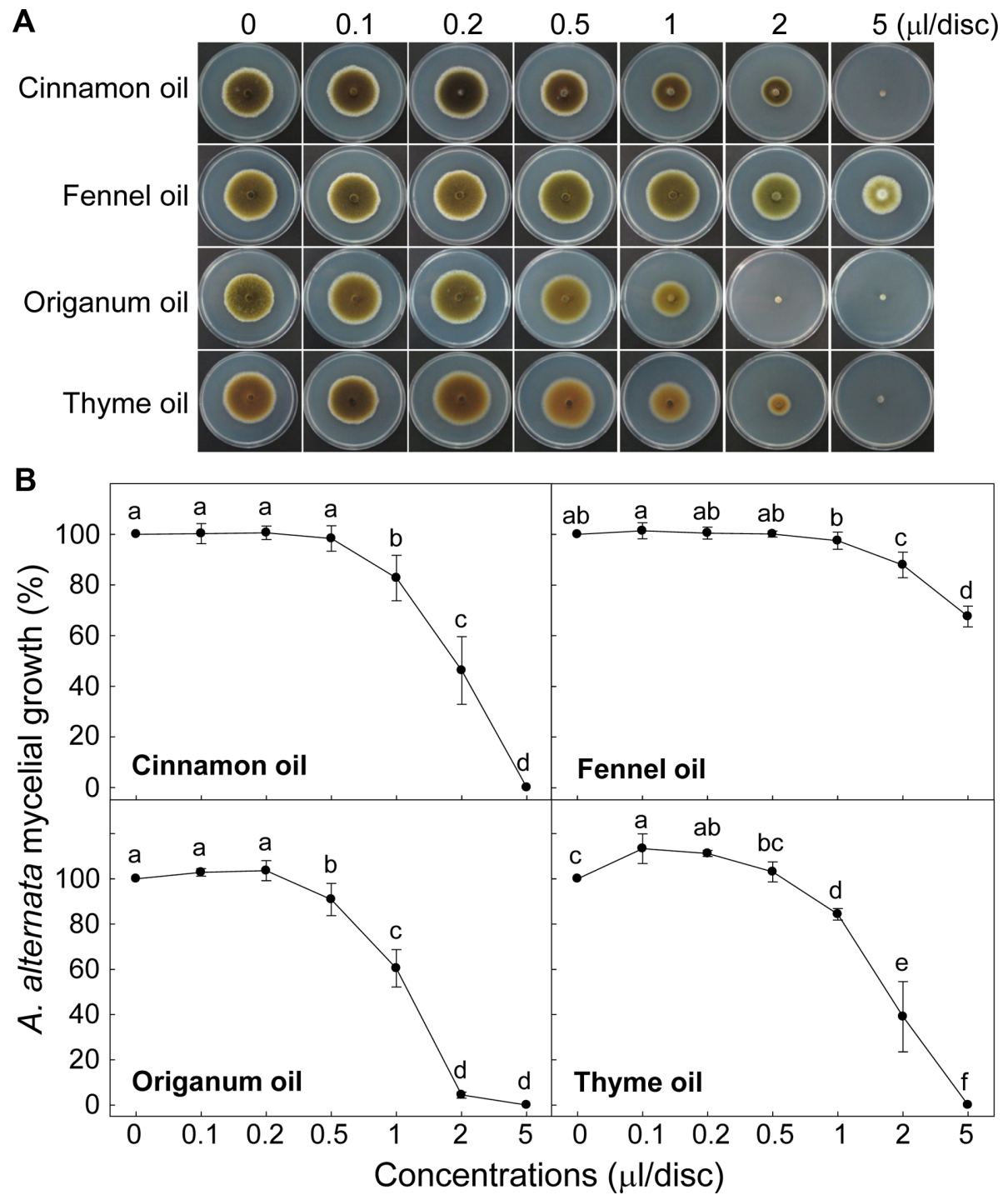

Fig. 2. Mycelial growth of Alternaria alternata inhibited by volatiles of four different plant essential oils, cinnamon oil, fennel oil, origanum oil and thyme oil. (A) Colony formation of A. alternata on PDA media by vapour treatment with different doses $(0,0.1,0.2,0.5,1,2$ and $5 \mu \mathrm{l} /$ disc) of each essential oil. Photos were taken at 5 days after the fungal incubation. (B) Relative mycelial growth inhibited by different doses of each essential oil shown as percentage of the fungal colonies on PDA. Error bars represent the standard errors of the mean mycelial growth of four independent experimental replications. Means followed by the same letter are not significantly different at $5 \%$ level by least significant difference test. The same letter above bars represented no significant difference between treatments.

mination similar to those of origanum oil. Increasing dose of thyme oil to $0.1,0.2,0.5$ and $1 \mu \mathrm{l} /$ disc resulted in decreases in the conidial germination by ca. $87.8,86.8,31.8$ and $17.9 \%$, respectively. However, more than $1 \mu \mathrm{l} /$ disc of origanum oil could not significantly increase the suppression efficacies against the conidial germination.

Different antifungal activities of the four plant essential oils against in vitro mycelial growth of $A$. alternata. In vitro mycelial growth of $A$. alternata was also differently inhibited by treatments with vapours of the four different plant essential oils (Fig. 2). At least $1 \mu \mathrm{l} /$ disc of cinnamon oil was necessary to reduce the mycelial growth with ca. $82.7 \%$ of the untreated control. Increasing dose to $2 \mu \mathrm{l} /$ disc of cinnamon oil resulted in ca. $46.2 \%$ of the mycelial growth and $5 \mu \mathrm{l} /$ disc of cinnamon oil completely inhibited the mycelial growth. Fennel oil has shown relatively lower antifungal activity against the mycelial growth compared to those of cinnamon oil. Most of the mycelia ca. $87.9 \%$ was still grown by $2 \mu \mathrm{l} /$ disc of fennel oil, and even increasing dose to $5 \mu \mathrm{l} /$ 
disc moderately inhibited the mycelial growth by ca. $67.6 \%$. Increasing origanum oils also arrested the mycelial growth in dose-dependent manner. At least $0.5 \mu \mathrm{l} / \mathrm{disc}$ of origanum oil reduced the mycelial growth by ca. $90.0 \%$, and $1 \mu \mathrm{l} / \mathrm{disc}$ reduced the mycelial growth by ca. $60.5 \%$. More than $2 \mu \mathrm{l} /$ disc showed strong antifungal activity against the mycelial growth that was completely arrested. Thyme oil showed different effects on the mycelial growth dependent on doses applied. Low doses 0.1 and $0.2 \mu \mathrm{l} /$ disc of thyme oil rather enhanced the mycelial growth but $0.5 \mu \mathrm{l} /$ disc of thyme oil did

A

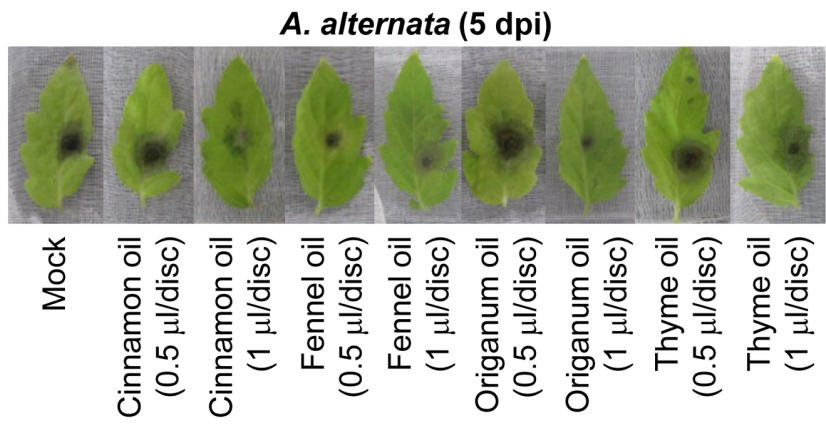

B

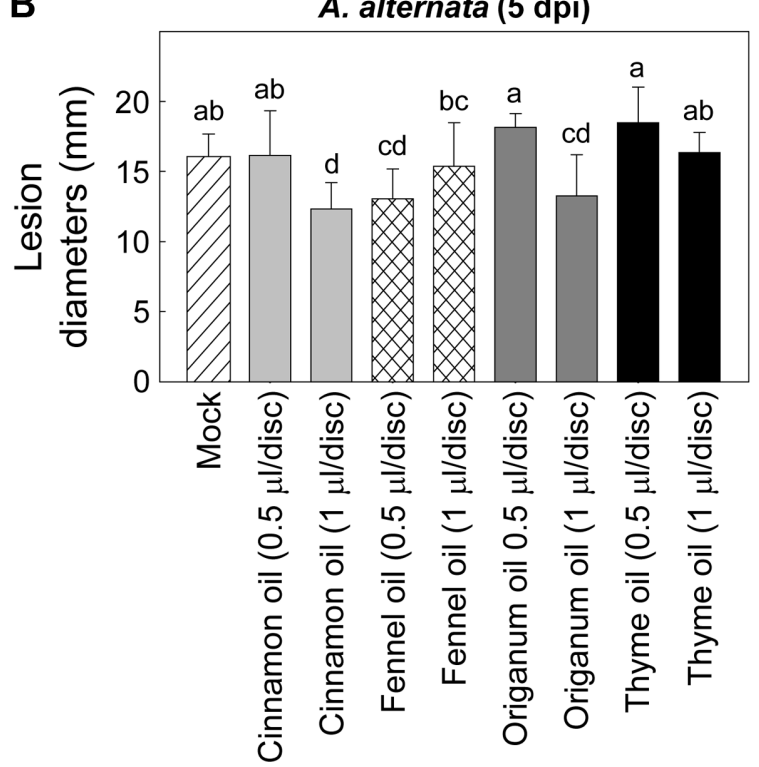

Fig. 3. Disease control of tomato Alternaria leaf spot by treatments with the four different plant essential oils. (A) Symptom development on the Alternaria alternata-inoculated tomato leaves at $5 \mathrm{dpi}$. (B) Lesion diameters $(\mathrm{mm})$ of the inoculated tomato leaves at $5 \mathrm{dpi}$ after treatment with plant essential oils. Error bars represent the standard errors of the mean lesion diameter of four independent experimental replications. Means followed by the same letter are not significantly different at $5 \%$ level by least significant difference test. The same letter above bars represented no significant difference between treatments. not alter the mycelial growth. One $\mu \mathrm{l} /$ disc slightly decreased the mycelial growth by ca. $84.3 \%$ and increasing to $2 \mu \mathrm{l} / \mathrm{disc}$ led to more decrease in the mycelial growth showing ca. $39.1 \%$ compared to that of untreated control.

Plant protection efficacies of the four plants essential oil vapours against Alternaria leaf spot. Treatment with vapours of the four plant essential oils resulted in different protection efficacies against tomato Alternaria leaf spot disease (Fig. 3). Treatments with cinnamon oil (1 $\mu \mathrm{l} / \mathrm{disc})$, fennel oil $(1 \mu \mathrm{l} / \mathrm{disc})$ and origanum oil $(1 \mu \mathrm{l} / \mathrm{disc})$ resulted in reduced diameters of necrotic lesion on the A. alternata-inoculated tomato leaves at $5 \mathrm{dpi}$, and there were no difference in protection efficacies. However, other treatments with cinnamon oil $(0.5 \mu \mathrm{l} / \mathrm{disc})$, fennel oil $(1 \mu \mathrm{l} / \mathrm{disc})$, origanum oil $(0.5 \mu \mathrm{l} / \mathrm{disc})$ and thyme oil ( 0.5 and $1 \mu \mathrm{l} / \mathrm{disc}$ ) did not change the lesion size compared to that of mock-treated control.

\section{Fungal development of $\boldsymbol{A}$. alternata on the tomato}

leaves. Growing behaviour of A. alternata on the detached tomato leaves with or without the plant essential oil vapours was observed under a light microscope (Fig. 4A). Many conidia germinated and germ-tube elongated in mock-, fennel oil- and thyme oil vapour-treated leaves, but distinct conidial germination and germ-tube elongation of $A$. alternata was not observed on cinnamon oil and origanum oil vapourtreated tomato leaves. Early conidial germination and germtube elongation on the tomato leaves were quantified at 6 hpi (Fig. 4B). On the mock-treated tomato leaf surface, ca. $46.2 \%$ of $A$. alternata conidia germinated and germ-tubes grew well with average length $8.47 \mu \mathrm{m}$. Treatments with vapours of the four plant essential oils ( $1 \mu \mathrm{l} /$ disc each) resulted in different conidial germination and germ-tube elongation of A. alternata on the leaves. Treatments with cinnamon oil and origanum oil vapours resulted in suppressed conidial germination of $A$. alternata shown by ca. $36.4 \%$ and ca. $36.1 \%$ germination rates, respectively. No significant reduction in the germination was found in the conidia treated with fennel oil and thyme oil vapours. More distinct suppression by cinnamon oil and origanum oil vapours was demonstrated by reduced germ-tube lengths of ca. $2.44 \mu \mathrm{m}$ and ca. $3.35 \mu \mathrm{m}$, respectively. Thyme oil vapour slightly reduced the germtube lengths with ca. $7.16 \mu \mathrm{m}$. 
A
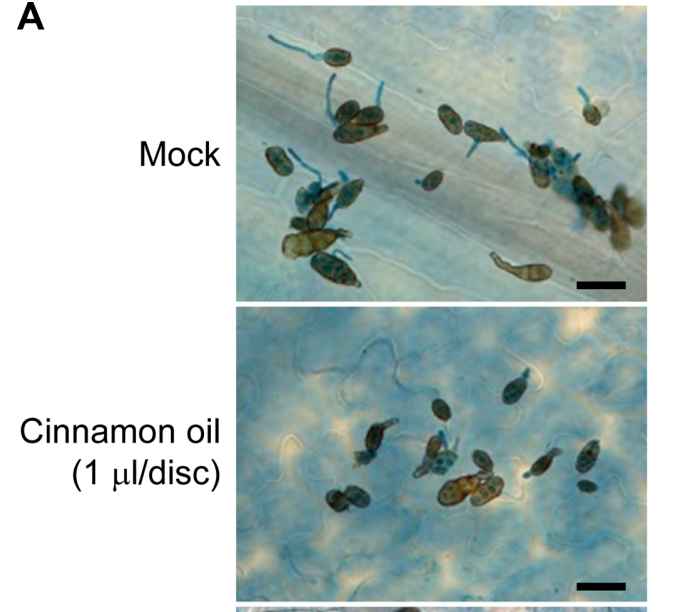

Fennel oil $(1 \mu \mathrm{l} / \mathrm{disc})$

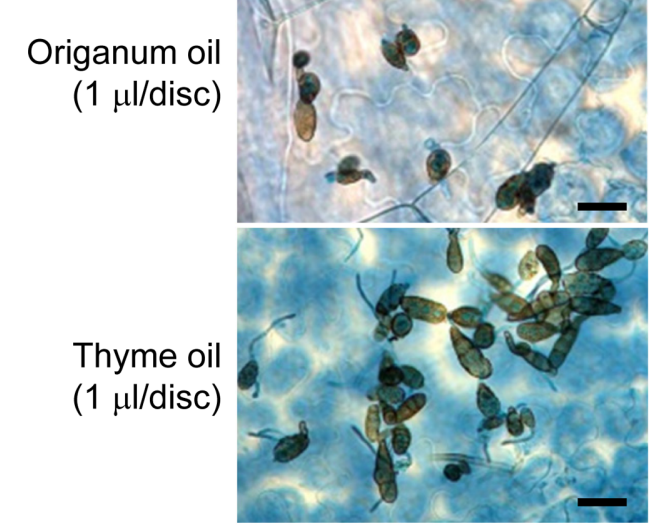

A. alternata (6 hpi)
B

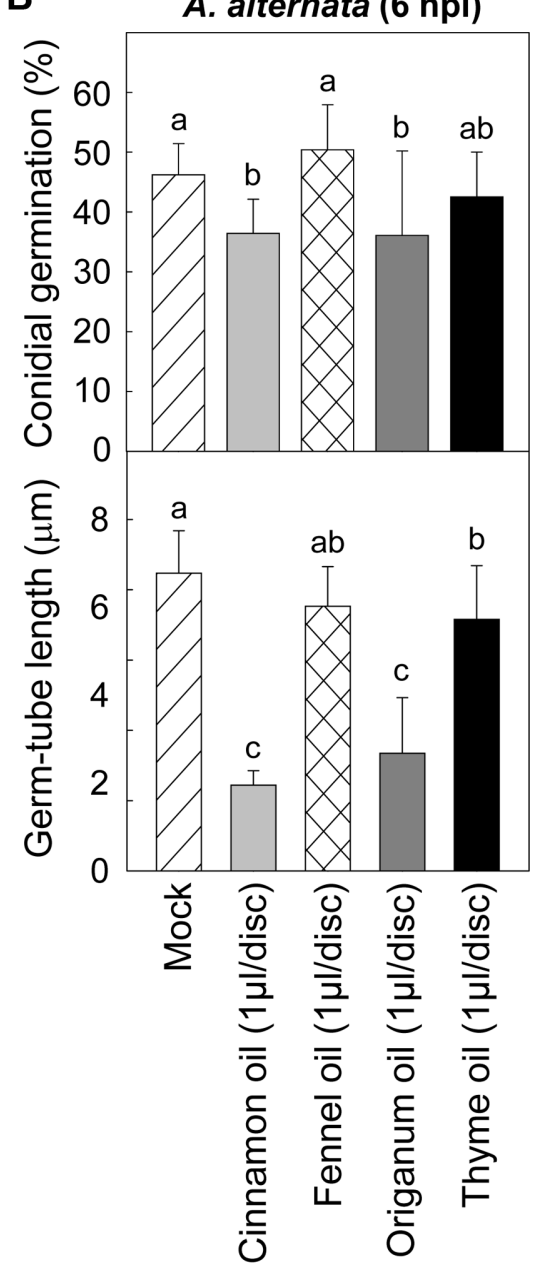

Fig. 4. Development of Alternaria alternata on the detached tomato leaves in the presence of plant essential oils. Conidial suspensions ( $2 x$ $10^{5} \mathrm{conidia} / \mathrm{ml}$ ) of $A$. alternata were drop-inoculated on the detached tomato leaves with or without plant essential oil vapour treatment $(1 \mu \mathrm{l} / \mathrm{disc})$. (A) Conidial germination and mycelial growth of A. alternata on the leaf tissue observed at $6 \mathrm{hpi}$ under a light microscope after fungal staining with lactophenol-trypan blue. Size bar=50 $\mu \mathrm{m}$. (B) Conidial germination and germ-tube elongation of $A$. alternata on the tomato leaves at $6 \mathrm{hpi}$. Error bars represent the standard errors of the means of four independent experimental replications. Means followed by the same letter are not significantly different at $5 \%$ level by least significant difference test. The same letter above bars represented no significant difference between treatments.

\section{Discussion}

Treatment with plant essential oils has been suggested as one of eco-friendly disease management during plant production and food preservation (Sakkas and Papadopoulou, 2017; Sivakumar and Bautista-Baños, 2014). Their volatile activities contribute to effective control efficacies of plant diseases, and various constituents originated from many antifungal plant essential oils have been identified (Lee et al., 2007; Neri et al., 2007; Oliva et al., 2015; Soylu et al., 2006; Wei and Shibamoto, 2010). In this study, vapours of the four plant essential oils, cinnamon oil, fennel oil, origanum oil and thyme oil, were evaluated to investigate whether they inhibit in vitro fungal development of $A$. alternata and protect 
tomato leaves against $A$. alternata infection in planta. These four plant essential oils have shown their in vitro antifungal activities against a variety of phytopathogenic fungi or in planta protection efficacies to broad ranges of fungal diseases in grape, pepper and tomato plants (Hong et al., 2015 Soylu et al., 2007, 2010; Walter et al., 2001). Cinnamon oil as a vapour significantly suppressed in vitro conidial termination and mycelial growth of C. gloeosporioides, and reduced anthracnose lesion development on pepper fruits (Hong et al., 2015). The four plant essential oils also exerted in vitro volatile antifungal activities dose-dependently against $F$. oxysporum f. sp. fragariae causing Fusarium wilt in strawberry plants in our previous study (Park et al., 2017). In the present study, vapour treatments of the four plant essential oils have showed differential antifungal activities during in vitro conidial germination and mycelial growth of $A$. alternata in dose-dependent manners. Generally, increasing doses of the plant essential oils highly limited in vitro growth of A. alternata. A variety of chemical constituents were indentified in cinnamon oil and origanum oil (Oliva et al., 2015; Soylu et al., 2006; Zamani-Zadeh et al., 2013). It remains elucidated which volatile constituents are related to antifungal activities of cinnamon oil and origanum oil against $A$. alternata. Recently, synergistic antifungal activities of origanum oil and thyme oil were demonstrated against mycelial growth of $F$. oxysporum f. sp. fragariae in our study (Park et al., 2017). Combined treatments with more than 2 plant essential oils may lead to enhanced antifungal activities against $A$. alternata as well, which remains investigated for the better disease control efficiencies.

In vitro antifungal activities of the three plant essential oils, cinnamon oil, fennel oil and origanum oil, were closely associated with in planta protection against $A$. alternata infection in tomato leaves without any phytotoxic effect. Arrested conidial germination and germ-tube elongation during the early infection stages of $A$. alternata observed under a light microscope were related to the retarded lesion development on the inoculated tomato leaves treated with cinnamon oil and origanum oil vapours. More investigation of morphological and subcellular changes of A. alternata by cinnamon oil and origanum oil vapours will provide better information on the antifungal activities of the two plant essential oils. Reducing A. alternata inoculum density in the tomato leaves by the plant essential oils can mediate in decrease of fruit rot during harvest and storage periods, because $A$. alternata also caused black rot mould in ripe tomato fruits (Abdel-Mallek et al., 1995; Bessadat et al., 2017; Gherbawy et al., 2018; Malathrakis, 1983; Xie et al., 2012). These three plant essential oils can be suggested to control other foliar diseases in tomato plants by bacterial and fungal infections simultaneously.

By contrast, thyme oil treatment did not mediate disease protection in planta, which may be related to increase in mycelial growth by low doses (0.1 and $0.2 \mu \mathrm{l} /$ paper disc) of thyme oil vapours in Fig. 2. Major components of thyme oil were identified as $p$-cymene, carvacrol and $\mathrm{X}$-terpnene, and they have shown antimicrobial activities, and none of them was reported to enhance fungal growth. It is necessary to answer why thyme oil vapour enhanced fungal growth of $A$. alternata. Disease controls by thyme oil treatment have been prevalently demonstrated in tomato fruits infected by $A$. alternata, Ponkan tangerine fruits infected by A. alternata and potato plants infected by A. solani (El-Mougy, 2009; Feng et al., 2011; Perina et al., 2015). We cannot exclude that increasing thyme oil dose or changing treatment method might be effective to control Alternaria leaf spot in tomato plants infected by $A$. alternata.

In conclusion, we applied vapours of the four different essential oils, cinnamon oil, fennel oil, origanum oil and thyme oil, to A. alternata causing leaf blight, stem canker and fruit rot in tomato plants. Cinnamon oil and origanum oil volatiles played roles in disease suppression of Alternaria leaf spot by the current detached leaf assay. Further evaluation for the tomato protection efficacies of the cinnamon oil and origanum oil volatiles under greenhouse conditions will be more valuable for integrated disease management eco-friendly.

\section{Conflicts of Interest}

No potential conflict of interest relevant to this article was reported.

\section{Acknowledgment}

This research was supported by Gyeongnam National University of Science and Technology (GNTech) Grant 2017 to Jeum Kyu Hong.

\section{References}

Abd-Alla, M. A., El-Mougy, N. S. and El-Gamal, N. G. 2009. Formula- 
tion of essential oils and yeast for controlling postharvest decay of tomato fruits. Plant Pathol. Bull. 18: 23-33.

Abdel-Mallek, A. Y., Hemida, S. K. and Bagy, M. M. K. 1995. Studies on fungi associated with tomato fruits and effectiveness of some commercial fungicides against three pathogens. Mycopathologia 130: 109-116.

Abu-El Samen, F. M., Goussous, S. J., Al-Shudifat, A. and Makhadmeh, I. 2016. Reduced sensitivity of tomato early blight pathogen (Alternaria solani) isolates to protectant fungicides, and implication on disease control. Arch. Phytopathol. Plant Protect. 49: 120-136.

Agamy, R., Alamri, S. A., Moustafa, M. F. and Hashem, M. 2013. Management of tomato leaf spot caused by Alternaria tenuissima Wiltshire using salicylic acid and Agrileen. Int. J. Agric. Biol. 15: 266-272.

Bessadat, N., Berruyer, R., Hamon, B., Bataille-Simoneau, N., Benichou, S., Kihal, M. et al. 2017. Alternaria species associated with early blight epidemics on tomato and other Solanaceae crops in northwestern Algeria. Eur. J. Plant Pathol. 148: 181-197.

Brame, C. and Flood, J. 1983. Antagonism of Aureobasidium pullulans towards Alternaria solani. Trans. Br. Mycol. Soc. 81: 621-624.

Chaerani, R. and Voorrips, R. E. 2006. Tomato early blight (Alternaria solani): the pathogen, genetics, and breeding for resistance. J. Gen. Plant Pathol. 72: 335-347.

Chavan, V. A., Yumlembam, R. A., Sewakram, K., Raghuwanshi and Borkar, S. G. 2017. Fungicide resistance in Alternaria leaf blight pathogen in tomato crop grown in Satara District. J. Pharmacogn. Phytochem. 6: 1736-1739.

Chen, Q., Xu, S., Wu, T., Guo, J., Sha, S., Zheng, X. et al. 2014. Effect of citronella oil on the inhibition of postharvest Alternaria alternata in cherry tomato. J. Sci. Food Agric. 94: 2441-2447.

Egusa, M., Ozawa, R., Takabayashi, J., Otani, H. and Kodama, M. 2009. The jasmonate signaling pathway in tomato regulates susceptibility to a toxin-dependent necrotrophic pathogen. Planta 229: 965-976.

El-Mougy, N. S. 2009. Effect of some essential oils for limiting early blight (Alternaria solani) development in potato field. J. Plant Prot. Res. 49: 57-62.

Esmailzadeh, M., Soleimani, M. J. and Rouhani, H. 2008. Exogenous applications of salicylic acid for inducing systemic acquired resistance against tomato stem canker disease. J. Biol. Sci. 8: 10391044.

Feng, W., Chen, J., Zheng, X. and Liu, Q. 2011. Thyme oil to control Alternaria alternata in vitro and in vivo as fumigant and contact treatments. Food Control 22: 78-81.

Gherbawy, Y., Hussein, M. A., Runge, F. and Spring, O. 2018. Molecular characterization of Alternaria alternata population isolated from Upper Egyptian tomato fruits. J. Phytopathol. 166: 709-721.

Grogan, R. G., Kimble, K. A. and Misaghi, I. 1975. A stem canker disease of tomato caused by Alternaria alternata f. sp. Iycopersici. Phytopathology 65: 880-886.

Hammami, I., Ben, H. A., Hamdi, N., Gdoura, R. and Triki, M. A. 2013.
Isolation and characterization of rhizosphere bacteria for the biocontrol of the damping-off disease of tomatoes in Tunisia. $C$. R. Biol. 336: 557-564.

Hong, J. K., Yang, H. J., Jung, H., Yoon, D. J., Sang, M. K. and Jeun, Y.-C. 2015. Application of volatile antifungal plant essential oils for controlling pepper fruit anthracnose by Colletotrichum gloeosporioides. Plant Pathol. J. 31: 269-277.

Hong, J. K., Kim, H. J., Jung, H., Yang, H. J., Kim, D. H., Sung, C. H. et al. 2016. Differential control efficacies of vitamin treatments against bacterial wilt and grey mould diseases in tomato plants. Plant Pathol. J. 32: 469-480.

Jambhulkar, P. P., Jambhulkar, N., Meghwal, M. and Ameta, G. S. 2016. Altering conidial dispersal of Alternaria solani by modifying microclimate in tomato crop canopy. Plant Pathol. J. 32: 508518.

Lee, S. O., Choi, G. J., Jang, K. S., Lim, H. K., Cho, K. Y. and Kim, J.-C. 2007. Antifungal activity of five plant essential oils as fumigant against postharvest and soilborne plant pathogenic fungi. Plant Pathol. J. 23: 97-102.

Lee, Y. H., Choi, C. W., Kim, S. H., Yun, J. G., Chang, S. W., Kim, Y. S. et al. 2012. Chemical pesticides and plant essential oils for disease control of tomato bacterial wilt. Plant Pathol. J. 28: 32-39.

Malathrakis, N. E. 1983. Alternaria stem canker of tomato in Greece. Phytopathol. Mediterr. 22: 33-38.

Meena, M., Zehra, A., Dubey, M. K., Aamir, M., Gupta, V. K. and Upadhyay, R. S. 2016. Comparative evaluation of biochemical changes in tomato (Lycopersicon esculentum Mill.) infected by Alternaria alternata and its toxic metabolites (TeA, $\mathrm{AOH}$, and AME). Front. Plant Sci. 7: 1408.

Neri, F., Mari, M., Brigati, S. and Bertolini, P. 2007. Fungicidal activity of plant volatile compounds for controlling Monilinia laxa in stone fruit. Plant Dis. 91: 30-35.

Oliva, M., Carezzano, M. E., Giuliano, M., Daghero, J., Zygadlo, J., Bogino, P. et al. 2015. Antimicrobial activity of essential oils of Thymus vulgaris and Origanum vulgare on phytopathogenic strains isolated from soybean. Plant Biol. 17: 758-765.

Pane, C., Celano, G., Villecco, D. and Zaccardelli, M. 2012. Control of Botrytis cinerea, Alternaria alternata and Pyrenochaeta lycopersici on tomato with whey compost-tea applications. Crop Prot. 38: 80-86.

Park, J. Y., Kim, S. H., Kim, N. H., Lee, S. W., Jeun, Y.-C. and Hong, J. K. 2017. Differential inhibitory activities of four plant essential oils on in vitro growth of Fusarium oxysporum $\mathrm{f}$. $\mathrm{sp}$. fragariae causing Fusarium wilt in strawberry plants. Plant Pathol. J. 33: 582-588.

Pérez-González, A., Cavazos-Arroyo, J., Rosano-Ortega, G., El Kassis, E. G. and Pérez-Armendáriz, B. 2016. Effect of emulsified oregano oil on Alternaria alternata (in vitro tests) and on Lycopersicum esculentum Mill. seedlings (in vivo tests). J. Agric. Environ. Sci. 5: 168-176.

Perina, F. J., Amaral, D. C., Fernandes, R. S., Labory, C. R. G., Teixeira, G. A. and Alves, E. 2015. Thymus vulgaris essential oil and thymol against Alternaria alternata (Fr.) Keissler: effects on growth, vi- 
ability, early infection and cellular mode of action. Pest Manag. Sci. 71: 1371-1378.

Prasad, V. and Upadhyay, R. S. 2010. Alternaria alternata f. sp. lycopersici and its toxin trigger production of $\mathrm{H}_{2} \mathrm{O}_{2}$ and ethylene in tomato. J. Plant Pathol. 92: 103-108.

Sakkas, H. and Papadopoulou, C. 2017. Antimicrobial activity of basil, oregano, and thyme essential oils. J. Microbiol. Biotechnol. 27: 429-438.

Schuhegger, R., Ihring, A., Gantner, S., Bahnweg, G., Knappe, C., Vogg, G. et al. 2006. Induction of systemic resistance in tomato by $N$-acyl-L-homoserine lactone-producing rhizosphere bacteria. Plant Cell Environ. 29: 909-918.

Sivakumar, D. and Bautista-Baños, S. 2014. A review on the use of essential oils for postharvest decay control and maintenance of fruit quality during storage. Crop Prot. 64: 27-37.

Song, W., Ma, X., Tan, H. and Zhou, J. 2011. Abscisic acid enhances resistance to Alternaria solani in tomato seedlings. Plant Physiol. Biochem. 49: 693-700.

Soylu, E. M. and Kose, F. 2015. Antifungal activities of essential oils against citrus black rot disease agent Alternaria alternata. J. Essent. Oil Bear. PI. 18: 894-903.

Soylu, E. M., Soylu, S. and Kurt, Ş. 2006. Antimicrobial activities of the essential oils of various plants against tomato late blight disease agent Phytophthora infestans. Mycopathologia 161: 119128.

Soylu, E. M., Kurt, Ş. and Soylu, S. 2010. In vitro and in vivo antifungal activities of the essential oils of various plants against tomato grey mould disease agent Botrytis cinerea. Int. J. Food Microbiol. 143: 183-189.

Soylu, S., Yigitbas, H., Soylu, E. M. and Kurt, Ş. 2007. Antifungal effects of essential oils from oregano and fennel on Sclerotinia sclerotiorum. J. Appl. Microbiol. 103: 1021-1030.

Spalding, D. H. 1980. Control of Alternaria rot of tomatoes by postharvest application of imazalil. Plant Dis. 64: 169-171.

Spletzer, M. E. and Enyedi, A. J. 1999. Salicylic acid induces resistance to Alternaria solani in hydroponically grown tomato. Phytopathology 89: 722-727.

Sukatta, U., Haruthaithanasan, V., Chantarapanont, W., Dilokkunanant, U. and Suppakul, P. 2008. Antifungal activity of clove and cinnamon oil and their synergistic against postharvest decay fungi of grape in vitro. Kasetsart J. 42: 169-164.

Walter, M., Jaspers, M. V., Eade, K., Frampton, C. M. and Stewart, A. 2001. Control of Botrytis cinerea in grape using thyme oil. Aust. Plant Pathol. 30: 21-25.

Wei, A. and Shibamoto, T. 2010. Antioxidant/lipoxygenase inhibitory activities and chemical compositions of selected essential oils. J. Agric. Food Chem. 58: 7218-7225.

Xie, G., Tan, S. and Yu, L. 2012. Morphological and molecular identification of pathogenic fungal of post-harvest tomato fruit during storage. Afr. J. Microbiol. Res. 6: 4805-4809.

Yang, J., Sun, C., Fu, D. and Yu, T. 2017a. Test for L-glutamate inhibition of growth of Alternaria alternata by inducing resistance in tomato fruit. Food Chem. 230: 145-153.

Yang, J., Sun, C., Zhang, Y., Fu, D., Zheng, X. and Yu, T. 2017b. Induced resistance in tomato fruit by $X$-aminobutyric acid for control of alternaria rot caused by Alternaria alternata. Food Chem. 221: 1014-1020.

Zamani-Zadeh, M., Soleimanian-Zad, S. and Sheikh-Zeinoddin, M. 2013. Biocontrol of gray mold disease on strawberry fruit by integration of Lactobacillus plantarum A7 with ajwain and cinnamon essential oils. J. Food Sci. 78: M1582-M1588. 